\title{
Photoacoustic Detection of Superoxide Using Oxoporphyrinogen and Porphyrin
}

\author{
Jean Michél Merkes, Magnus Rueping, ${ }^{\mathrm{I}, \dagger}$ Fabian Kiessling, ${ }^{\ddagger}$ and Srinivas Banala*,l, \\ 'Institute of Organic Chemistry, RWTH Aachen University, Landoltweg 1, D 52074 Aachen, Germany. \\ ${ }^{\ddagger}$ Institute for Experimental Molecular Imaging, University Clinic, and Comprehensive Diagnostic Center Aachen, RWTH \\ Aachen University, Forckenbeckstrasse 55, D52074 Aachen, Germany. \\ ${ }^{\dagger}$ KAUST Catalysis Center (KCC), King Abdullah University of Science and Technology (KAUST), Thuwal 23955-6900, \\ Saudi Arabia.
}

KEYWORDS: Superoxide species; photoacoustic imaging; oxoporphyrinogen; ROS trapping; stimuli-responsive detection; trigger-induced redshift

\begin{abstract}
The superoxide $\left(\mathrm{O}_{2}{ }^{--}\right)$ion is a highly reactive oxygen species involved in many diseases, hence its non-invasive detection is desirable to identify the onset of pathological processes. Here, we employed photoacoustic (PA) spectroscopy, which enables imaging at ultrasound resolution with sensitivity of optical modality, for the first time to detect $\mathrm{O}_{2}{ }^{\bullet-}$, using stimuliresponsive contrast agents. Meso (3, 5-di-tert-butyl 4-hydroxyphenyl) porphyrins and oxoporphyrinogens were used as PA contrast agents, which trap the $\mathrm{O}_{2}{ }^{-}$and enable its detection. The trapped $\mathrm{O}_{2}{ }^{--}$increased the PA signal amplitude of chromophores up to 9.6fold, and induced a redshift in the PA signal maxima of up to $225 \mathrm{~nm}$. Therefore, these trigger-responsive probes may be highly valuable as smart diagnostic PA probes to investigate pathological events stimulated by $\mathrm{O}_{2}{ }^{\bullet-}$ species.
\end{abstract}

Reactive oxygen species (ROS) are highly aggressive, biochemically produced molecules that play important roles in physiological and pathological processes. ROS are a set of short-lived species comprised of $\mathrm{O}_{2}{ }^{\bullet-}, \mathrm{H}_{2} \mathrm{O}_{2}, \mathrm{HO}^{\bullet}$ and $\mathrm{HO}_{2}{ }^{\bullet}$, of which the primary super oxide ion $\left(\mathrm{O}_{2}{ }^{-}\right)$is produced from oxygen via cellular electron transfer processes. It is well-established that uncontrolled $\mathrm{O}_{2}{ }^{\circ}$ production is involved in diverse pathological processes, especially in inflammatory disorders like atherosclerosis, inflammatory bowel diseases, and rheumatoid arthritis as well as in cancer. ${ }^{1}$ The generated $\mathrm{O}_{2}{ }^{-{ }^{-}}$undergoes further reactions to the secondary ROS species, hydrogen peroxide $\left(\mathrm{H}_{2} \mathrm{O}_{2}\right)$ and hydroxyl radical $\left(\mathrm{HO}^{\bullet}\right){ }^{2}$. To image the onset of diseases and elevated production of ROS, previous studies employed ROS-reactive (chemically irreversible) probes, which give a readable signal upon reaction that is correlated to the amount of produced ROS. ${ }^{1,3}$ Among ROS-imaging, fluorescence based methods are highly prevalent in literature (up to $75 \%$ of previous reports), followed by electron paramagnetic resonance (EPR) spectroscopy and colorimetric methods. ${ }^{3,4}$ However, optical methods suffer from photon scattering and diffusion which limits the detection depth to ca. $0.1 \mathrm{~mm}$; EPR as well as colorimetric methods are suitable only for in vitro applications.

Photoacoustic (PA) imaging circumvents these limitations by combining optical imaging with ultrasound (US), and is highly suitable for in vivo imaging. ${ }^{5,6}$ As ultrasound waves show less attenuation in tissues in comparison to light, PA imaging can be possible at higher depths (up to $7 \mathrm{~cm}$ ) with US spatial resolution (up to $50 \mu \mathrm{m}$ ) ${ }^{7,8}$ Moreover, the generated PA signal is directly proportional to the amount of light absorbing material present, thus increasing PA sensitivity to the levels of optical modalities (up to sub-nano molar). ${ }^{8}$ The light absorbing agents can be of either endogenous or exogenous origin, which are irradiated with a nonionizing, low energy laser light to generate PA signals via thermo-elastic expansion. ${ }^{9,10} \mathrm{PA}$ imaging has already found potential clinical applications and several translational studies are ongoing, ${ }^{11}$ e.g. for the early detection of malignant tumors, ${ }^{12-14}$ the characterization of inflammatory bowel diseases ${ }^{15}$ the localization of sentinel lymph nodes ${ }^{16}$ as well as the assessment of tissue hypoxia, ${ }^{17}$ tumor vasculature, ${ }^{18}$ and fat metabolism. ${ }^{19}$ Therefore, PA imaging of short-lived ROS is an exciting next step to advance this modality.

For the PA detection of ROS, it is necessary to develop probes selectively reactive to $\mathrm{O}_{2}{ }^{\bullet-}, \mathrm{HO}{ }^{\bullet}$ and/or $\mathrm{H}_{2} \mathrm{O}_{2}{ }^{20}{ }^{2}$ The latter species was imaged with the aid of phthalocyanine, that after reaction cleaved attached soluble groups and increased the nanoparticle size and thereby the PA signal intensity. ${ }^{21}$ Alternatively, horseradish peroxidase (HRP) and its substrate were entrapped in a liposome, which upon reaction with $\mathrm{H}_{2} \mathrm{O}_{2}$ gave a green dye with increased PA-signal. ${ }^{22}$ To make previously investigated exogenous PA probes ROS-sensitive, extensive optimization is necessary as they are 'always PA active'. ${ }^{23-28}$ Hence, it is advantageous to explore new strategies to prepare ROS-responsive PA chromophores. ${ }^{29,30}$ Ideally, the desired trigger-responsive probes convert from a PAoff to a PA-on state and/or exhibit a shift in the absorption maxima (preferably into the NIR-range) after the reaction of a particular ROS species. ${ }^{31,32}$ 


\section{Previous concepts}

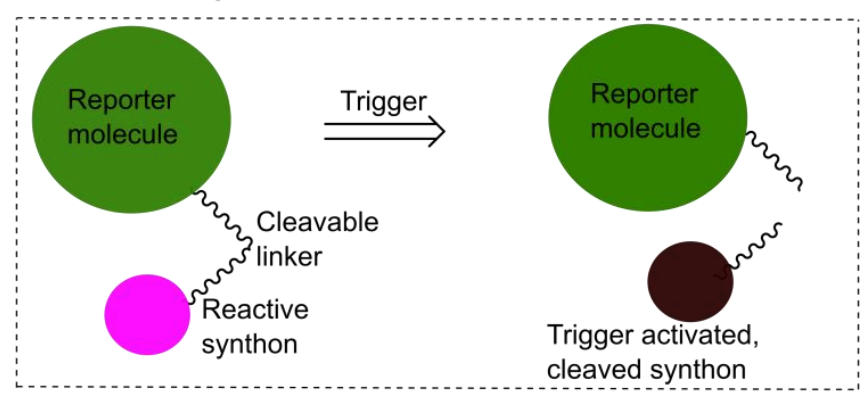

\section{Our hypothesis}

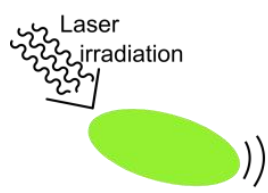

PA inactive
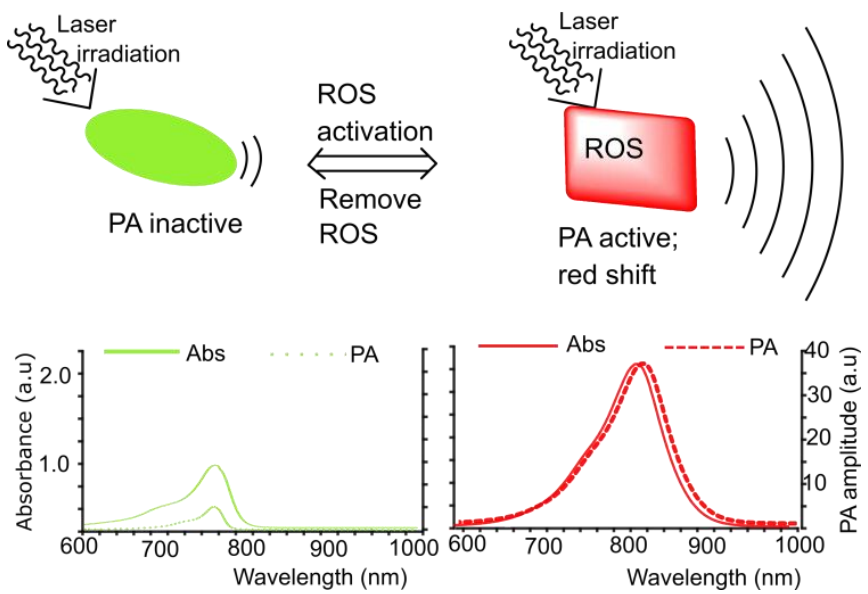

Figure 1.Conceptual illustration of reversible ROS-trapping by probe for PA generation (depicted absorption and PA spectra changes are only for hypothetical purpose).

Previous trigger-responsive concepts are, typically, based on a cleavable group attached to the reporter probe (Figure 1, top, e.g. as in fluorophore-quencher conjugates). After the reaction of reactive species, the cleaved reporter molecule generates a stronger signal. ${ }^{33}$ In this work, we describe a novel approach without any cleavable group, but trapping the trigger by the reporter molecule. In comparison to the cleavable probes it is of advantage that the consumption of the substrates does not continue and thus is not so much time dependent. Therefore, non-covalent trapping methods may generate a lower background signal. Our probe changes optical and photoacoustic properties by non-covalent interactions with the super oxide ion $\left(\mathrm{O}_{2}^{{ }^{\bullet-}}\right)$. To the best of our knowledge, this is the first time such a concept is described using a small molecule dye, and is applied to image $\mathrm{O}_{2}{ }^{--}$by PA imaging. We report that oxoporphyrinogen 2 is suitable to trap the $\mathrm{O}_{2}{ }^{\bullet-}$, and gave a 9.6-fold increase in the PA signal accompanied by an $89 \mathrm{~nm}$ redshift, and is detectable in up to $3 \mu \mathrm{M}$.

\section{Experimental section}

a) Free base porphyrin (1-2H): A dry round bottomed flask equipped with a magnetic stirring bar was charged with $725 \mathrm{mg}$ (3.1 mmol, 1.02 eq.) of 3,5-di tert-butyl-4-hydroxy benzaldehyde, and $210 \mathrm{mg}$ (3.02 mmol, 1 eq.) of hydroxylamine-hydrochloride $\left(\mathrm{NH}_{2} \mathrm{OH} \cdot \mathrm{HCl}\right)$ and dried on $\mathrm{H} . \mathrm{V}$. To this mixture $15 \mathrm{~mL}$ abs chlorobenzene was added, and the suspension was degassed for 10 mins by argon bubbling, $210 \mu \mathrm{L}(203.1 \mathrm{mg}, 3.03 \mathrm{mmol}, 1 \mathrm{eq}$.) of pyrrole was added. The mixture was stirred for $24 \mathrm{~h}$ at r.t., followed by addition of $10 \mathrm{~mL}$ nitrobenzene and the mixture was placed in a pre-heated oil bath at $130{ }^{\circ} \mathrm{C}$ for $2 \mathrm{~h}$. After cooling the reaction, solvents were removed by vacuum distillation, and the residual solid was washed with $\mathrm{NaHCO}_{3}(2 \times 30 \mathrm{~mL})$, extracted with $(4 \times 50 \mathrm{~mL}) \mathrm{CH}_{2} \mathrm{Cl}_{2}$, dried over $\mathrm{Na}_{2} \mathrm{SO}_{4}$ and concentrated on rotary evaporator. The dry mixture was dissolved in $\mathrm{CH}_{2} \mathrm{Cl}_{2}$, precipitated by the addition of methanol (ca. 1:10 ratio) and centrifuged (10 min, $6000 \mathrm{rpm})$. The supernatants were removed and the obtained solids were dried in H.V. to obtain $218 \mathrm{mg}(0.77 \mathrm{mmol}, 25.5 \%)$ of microcrystalline product 1-2H. ${ }^{1} \mathrm{H}$ NMR (in $\left.\mathrm{CD}_{2} \mathrm{Cl}_{2}, 400 \mathrm{MHz}\right) \delta$ in ppm: $8.93(s, 8 \mathrm{H}), 8.05(s, 8 \mathrm{H}), 5.6(s, 4 \mathrm{H}), 1.64(s, 72 \mathrm{H}),-2.74(\mathrm{br}, 2 \mathrm{H}) ;{ }^{13} \mathrm{C} \mathrm{NMR}\left(\mathrm{in} \mathrm{CDCl}{ }_{3}, 151 \mathrm{MHz}\right) \delta$ in ppm: $153.4,133.9,133.4,131.8,121,34.6,34.4,30.7,29.7 . ;$ HRMS (ESI, $+\mathrm{Ve}, \mathrm{C}_{76} \mathrm{H}_{94} \mathrm{~N}_{4} \mathrm{O}_{4}, \mathrm{M}_{\text {Calc. }}: 1126.72751$ ): found = $1127.73499\left([\mathrm{M}+\mathrm{H}]^{+}\right)$

\section{b) Synthesis of Oxoporphyrinogen (2) using TBAF:}

A dry flask was charged with $19 \mathrm{mg}(16.8 \mu \mathrm{mol})$ of $\mathbf{1 - 2 H}$ and $10 \mathrm{~mL}$ of abs. $\mathrm{CH}_{2} \mathrm{Cl}_{2}$, followed by $70 \mathrm{mg}$ of TBAF $(221 \mu \mathrm{mol}, 13$ eq.). The mixture was stirred at r.t. for $2 \mathrm{~h}$, and the obtained dark blue mixture was poured in water, extracted with $\mathrm{CH}_{2} \mathrm{Cl}_{2}$ and dried over $\mathrm{Na}_{2} \mathrm{SO}_{4}$. The solvent was removed on rotary evaporator and the reaction mixture was eluted through a short silicagel column using $\mathrm{CH}_{2} \mathrm{Cl}_{2}$ /hexane. The collected fractions were dried on rotary evaporator. The product was precipitated in $\mathrm{CH}_{2} \mathrm{Cl}_{2} / \mathrm{MeOH}$ and dried in H.V. to obtain $13.2 \mathrm{mg}(69.5 \%)$ of blue microcrystalline product 2. 
c) Oxoporphyrinogen (2) using $\mathrm{KO}_{2}$ : To $9.6 \mathrm{mg}(8.5 \mu \mathrm{mol})$ of $\mathbf{1 - 2 H}$ in $\mathrm{CD}_{2} \mathrm{Cl}_{2}(0.65 \mathrm{~mL})$ and 18 -crown-6 (47 $\left.\mu \mathrm{mol}\right)$, was added $\mathrm{KO}_{2}$ (total $8 \mathrm{mg}, 110 \mu \mathrm{mol}$, in 8 steps over $3 \mathrm{~h}$ ) in a NMR tube for titration. Finally, the reaction mixture was poured into water and extracted with $\mathrm{CH}_{2} \mathrm{Cl}_{2}$. The reaction mixture was eluted through a short silicagel column and the product was precipitated in excess $\mathrm{CH}_{2} \mathrm{Cl}_{2} / \mathrm{MeOH}$ to obtain $5 \mathrm{mg}(52 \%)$ of $2 .{ }^{1} \mathrm{HNMR}$ (in $\left.\mathrm{CD}_{2} \mathrm{Cl}_{2}, 400 \mathrm{MHz}\right): 10.11$ (br $\left.s, 4 \mathrm{H}\right), 7.53(s, 8 \mathrm{H}), 6.81(s, 8 \mathrm{H}), 1.33(s, 72 \mathrm{H})$; ${ }^{13} \mathrm{C} \mathrm{NMR}$ (in $\mathrm{CDCl}_{3}, 151 \mathrm{MHz}$ ) $\delta$ in ppm: 147.7, 134.4, 131.4, 119.7, 35.5, 30.7, 29.7, 29.4; MS:(ESI, + Ve, $\mathrm{C}_{76} \mathrm{H}_{92} \mathrm{~N}_{4} \mathrm{O}_{4}, \mathrm{Calc}$. 1124.71186): 1125.72034 for $[\mathrm{M}+\mathrm{H}]^{+}$)

d) Photoacoustic Imaging: The preclinical PA device VEVO LAZR 2100 (from Fujifilm Visual Sonics Inc., Amsterdam, NL) was equipped with a LZ 250 transducer (from Visual Sonics Inc.), having a centre frequency of $21 \mathrm{MHz}$ was used for all measurements (26 db gain). The VEVO LAZR built-in pulse laser (wavelengths between $680-970 \mathrm{~nm}$ ) was used with a step size of $5 \mathrm{~nm}$ in spectroscopy mode. The device was warmed up for $30 \mathrm{~min}$ and its energy was calibrated using an internally programmed and builtin sensor by placing it $c a 10-11 \mathrm{~mm}$ above the sensor before the measurements. Tube phantoms were measured at 10-11 mm depth, i.e. the distance between the transducer and tube, in a water chamber and a total of 59 frames $(5 \mathrm{~nm}$ steps) were recorded. The Vevo 2100 software was used for data processing. During the experiments, all variable parameters were kept constant i.e. photoacoustic gain, laser power, focus depth, frame averaging, and frame rate.

\section{Results and discussion}

Previously, the oxoporphyrinogen (OxP, 2) was synthesized via aerial oxidation of meso tetrakis (3,5-di tert-butyl-4hydroxyphenyl) porphyrin (1-2H). ${ }^{34} \mathbf{2}$ was also obtained by treating $\mathbf{1 - 2 H}$ with fluoride ions (tetrabutylammonium fluoride, TBAF), followed by removing $\mathrm{F}^{-}$from the complex. ${ }^{35}$ Both, porphyrinoids $\mathbf{2}$ and $\mathbf{1 - 2 H}$, showed a weak absorption band in the range $>700$ $\mathrm{nm}$, but the absorption maxima upon complexation with $\mathrm{F}^{-}$was shifted to above $800 \mathrm{~nm}\left(\mathbf{2}: \mathrm{F}^{-}\right)$. As basicity of $\mathrm{F}^{-}$is similar to that of $\mathrm{O}_{2}{ }^{\bullet-},{ }^{36}$ we believed that $\mathrm{O}_{2}^{\bullet-}$ could perform a similar complexation with $\mathbf{2}$ (and with $\mathbf{1 - 2 H}$ ), and thus motivated us to carry out $\mathrm{O}_{2}^{\bullet-}$-responsive PA imaging studies.

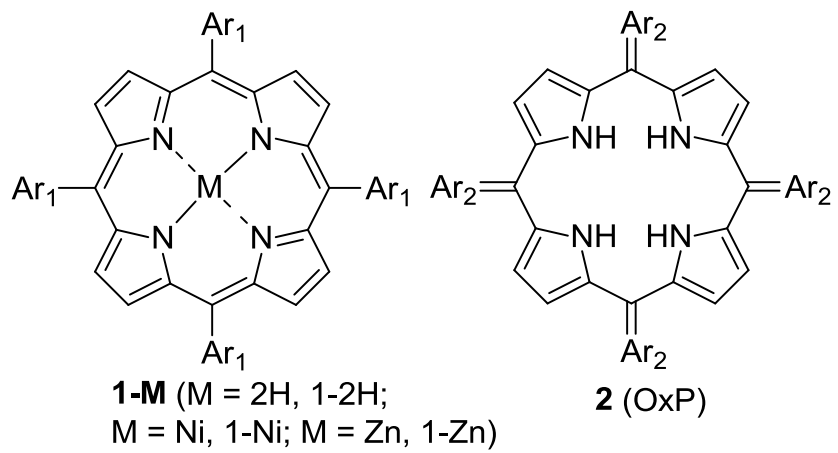

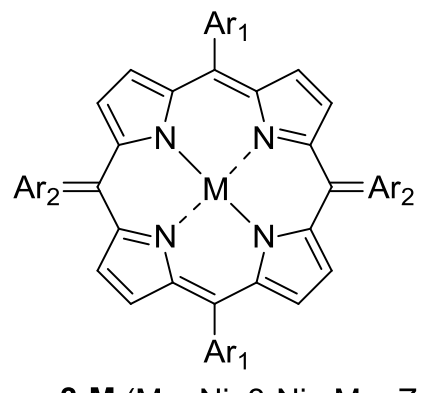<smiles>CC(C)(C)[14C]=C1C=C(C(C)(C)C)C(=O)C(C(C)(C)C)=C1</smiles>

Chart 1. Structures of the meso(3,5-di tert-butyl-4-hydroxyphenyl) porphyrin1, and from it derived oxidized forms 2 and 3.

\section{Synthesis of tetrapyrrole probes}

The synthesis of $\mathbf{1 - 2 H}$ was reported by Milgrom in a one-pot condensation of 3,5-di tert-butyl-4-hydroxy benzaldehyde and pyrrole in hot propanoic acid (classical Adler-Longo conditions), which gave $13 \%$ yield after chromatography and recrystallization. ${ }^{34}$ Lindsey et al reported generally applicable modified conditions for the synthesis of porphyrins using $\mathrm{BF}_{3} . \mathrm{OEt}_{2},{ }^{37} \mathrm{but}$ those did in our case not result in $\mathbf{1 - 2 H}$. However, $\mathbf{1 - 2 H}$ was successfully synthesized by us using $\mathrm{NH}_{2} \mathrm{OH} \cdot \mathrm{HCl}$ catalyzed condensation (see SI) ${ }^{38}$ The product $\mathbf{1 - 2 H}$ was obtained in $25 \%$ yield without chromatography but by precipitation in methanol, as purple micro crystals, and identified with ${ }^{1} \mathrm{H}-\mathrm{NMR}$, UV-vis absorption and MS spectra. Metal ions $\left(\mathrm{Ni}^{(\mathrm{II})}, \mathrm{Zn}^{(\mathrm{II})}\right.$ ) were incorporated by refluxing 1-2H with $\mathrm{Ni}(\mathrm{OAc})_{2}$ and $\mathrm{Zn}(\mathrm{OAc})_{2}$ (see SI), and 1-Ni, 1-Zn were obtained as red and dark green micro crystals, respectively.

Then, oxoporphyrinogen chromophore 2 was prepared by treating 1-2H with excess TBAF at r.t. for $2 \mathrm{~h}$ and subsequently filtering it through a short silicagel plug followed by precipitation in $\mathrm{MeOH} .{ }^{35}$ Similarly, the product 2 can be obtained by reaction of $\mathbf{1 -}$ $2 \mathbf{H}$ with excess $\mathrm{KO}_{2} / 18$-crown-6 (18-C-6), subsequent aqueous washing and silica gel filtration. 18-C-6 was required to complex 
$\mathrm{K}^{+}$ion and to generate 'free' $\mathrm{O}_{2}{ }^{\bullet-}$ in organic solution. The obtained product $\mathbf{2}$ from $\mathrm{TBAF}_{\text {or }} \mathrm{KO}_{2}$ reaction with $\mathbf{1 - 2 H}$ has identical characteristics (Figure. S37). The ${ }^{1} \mathrm{H}-\mathrm{NMR}$ spectrum of $\mathbf{2}$ in the presence of $\mathrm{F}$ showed no loss of any protons, but only upfield shift of core NH protons (Figure. S38), confirming the non-covalent complexation of $\mathrm{F}$. The changes in ${ }^{1} \mathrm{H}-\mathrm{NMR}$ chemical shifts of 2 to the added $\mathrm{KO}_{2} / 18-\mathrm{C}-6$ (Figure S39) were similar to that of TBAF - upfield shift of internal NH protons, indicating a similar mode of binding. Furthermore, changes in ${ }^{1} \mathrm{H}-\mathrm{NMR}$ chemical shifts during the titrations of 1-2H with $\mathrm{KO}_{2} / 18-\mathrm{C}-6$ and with TBAF confirmed that both ionic species oxidize 1-2H to $\mathbf{2}$ and formed a complex with the core NH protons (see Figure S41, Figure S42). The absorption spectra of $\mathbf{2}$ in the presence of $\mathrm{O}_{2}{ }^{--}$(and $\mathrm{F}^{-}$) showed a stronger redshifted band than that of pristine $\mathbf{2}$, thus also confirming the complexation (Figure. 2b). Therefore, it can be concluded that $\mathbf{2}$ traps the $\mathrm{O}_{2}^{\boldsymbol{\bullet}^{-}}$(and $\mathrm{F}^{-}$) non-covalently and is suitable for $\mathrm{PA}$ imaging of $\mathrm{O}_{2}^{\bullet-}$.

In order to evaluate whether the internal pyrrolic NHs are necessary for $\mathrm{O}_{2}{ }^{\bullet-}$-binding, and whether metallated porphodimethenes (3-Ni and 3-Zn) exhibit superior PA properties than 2, the porphyrins 1-Ni and 1-Zn were oxidized via treatment with excess TBAF at r.t. for $2 \mathrm{~h}$, and purified by a short-plug chromatography. ${ }^{1} \mathrm{H}-\mathrm{NMR}$ analysis of 1-Ni, 1-Zn titration with TBAF (Figure S43, Figure S44) showed similar spectral changes as in $\mathbf{1 - 2 H}$, and yielded 3-M as the final products. This confirms that metalloporphyrins can be activated by $\mathrm{F}^{-}$. However, when the oxidation of $\mathbf{1 - Z n}$ was carried out with $\mathrm{KO}_{2} / 18-\mathrm{C}-6, \mathbf{3}-\mathbf{Z n}$ could not be isolated but a decomposition process was observed. Moreover, the stability of 3-M was found to be lower than that of $\mathbf{2}$, possibly due to disproportionation to the respective porphyrins in solution (as observed in ${ }^{1} \mathrm{H}-\mathrm{NMR},>5 \%$ of 1-Ni in 3-Ni, Figure S45). This lability of 3-M was also perceived by visible colour changes to the eye (from bright green to a reddish shade) and UV-vis (appearance of Soret band). This implies that metal-free $\mathbf{2}$ is better suited as $\mathrm{O}_{2}{ }^{\bullet-}$-responsive PA probe than the metallated ones.

\section{Photoacoustic and absorption spectra measurements}

Photoacoustic spectroscopy experiments were carried out using DMF solutions of oxoporphyrinogen 2, 3-Ni, 3-Zn, and porphyrin 1-M (M=2H, Zn, Ni), and ICG as standard. The Vevo LAZR 2100 (Visual Sonics Inc.) photoacoustic scanner was used to measure PA signals in polythene tubes $(i . d=0.38 \mathrm{~mm})$ filled with different porphyrinoid solutions in a water chamber phantom at excitations between $680-970 \mathrm{~nm}$.

a

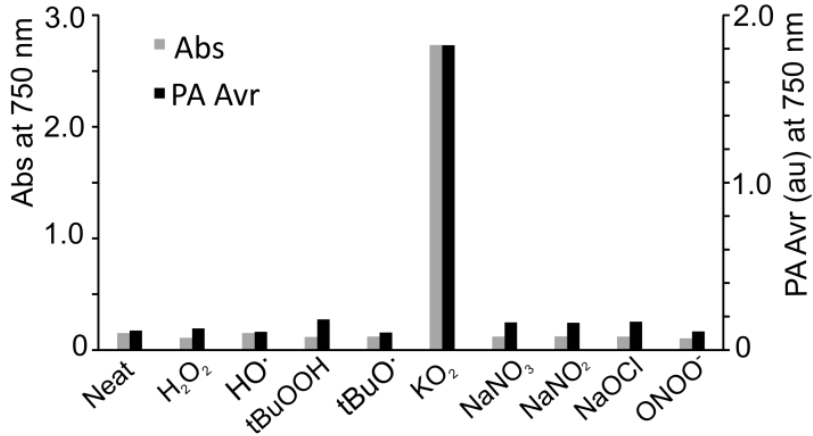

b

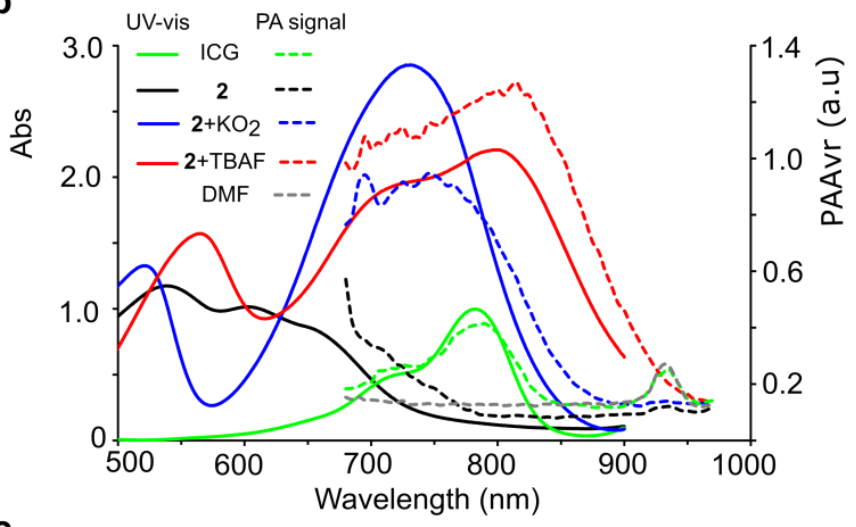

C

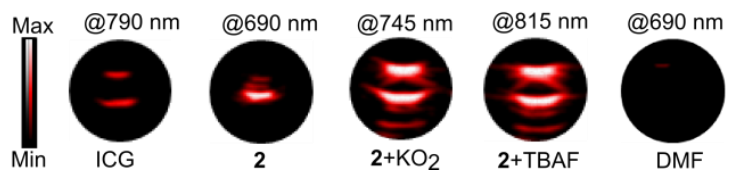

Figure2.a) The change in absorbance at $750 \mathrm{~nm}$ in response to given reactive trigger species ( $25 \mu \mathrm{M}$ in DMF) is shown. b) UV-vis (full lines, left axis) and PA spectra (dotted lines, right axis) of ICG $(7.8 \mu \mathrm{M}), \mathbf{2}(100 \mu \mathrm{M}), \mathbf{2}+\mathrm{KO}_{2}(25 \mu \mathrm{M})$ and $2+\mathrm{TBAF}(25 \mu \mathrm{M})$. To induce 
trigger response, to $25 \mu \mathrm{M}$ solution of 2 , excess $\mathrm{KO}_{2} / 18-\mathrm{C}-6$ and TBAF were added, and the other triggers were added to $125 \mu \mathrm{M}$ solutions

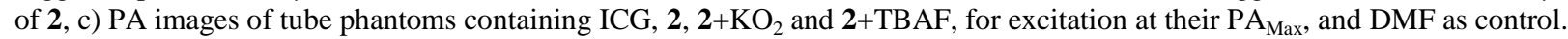

The measured PA spectrum of $2(100 \mu \mathrm{M})$ was in agreement with the absorption spectrum, featuring a sharply decreasing band from $680 \mathrm{~nm}$ to $750 \mathrm{~nm}$ (see Figure $2 \mathrm{~b}$ ). We then tested the PA properties of $\mathbf{2}$ in the presence of $\mathrm{O}_{2}^{\bullet-}$ and $\mathrm{F}^{-}$, as well as with other reactive oxygen and nitrogen species (Figure 2a). An excess of TBAF, $\mathrm{KO}_{2} / 18-\mathrm{C}-6$ was added to a solution of 2 (25 $\mu \mathrm{M}$ ) and the PA signal was measured. To our satisfaction, $\mathrm{O}_{2}{ }^{--}$addition $\left(2+\mathrm{KO}_{2}\right)$ resulted in a 9.6-fold stronger PA-signal (PA signal of 2 at 25 $\mu \mathrm{M}$ was only at background level, see Figure S19, hence $100 \mu \mathrm{M}$ solution was taken and the concentration normalized for comparison), with a redshift of $89 \mathrm{~nm}$ (observed PA maximum, $\mathrm{PA}_{\mathrm{Max}}$ : $745 \mathrm{~nm}$ ) (Figure 2b). When PA spectroscopy of increasingly diluted solutions of $\mathrm{O}_{2}{ }^{\bullet-}$-activated 2 was performed, we found that PA signals were detectable down to $3 \mu \mathrm{M}$ (Figure S20). Furthermore,

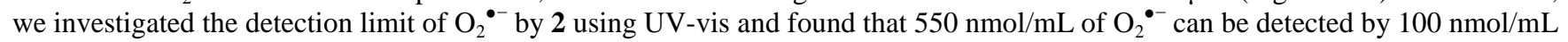
of 2 in solution. The $\mathrm{O}_{2}{ }^{\bullet-}$ concentration in healthy mitochondria is $0.1 \mathrm{pmol} / \mathrm{mL}$, but increases in varicosity as high as $>69$

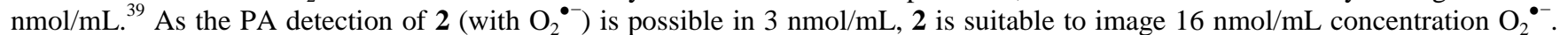
The effect of other ROS triggers $\left(\mathrm{H}_{2} \mathrm{O}_{2},{ }^{t} \mathrm{BuOOH} \mathrm{OCl}^{-},{ }^{\bullet} \mathrm{OH}\right.$, and ${ }^{\mathrm{t}} \mathrm{BuO}^{\bullet}$; radicals were generated by $\mathrm{Fe}^{(\mathrm{II})}$ addition) and $\mathrm{RNS}\left(\mathrm{NO}_{2}{ }^{-}\right.$, $\mathrm{NO}_{3}{ }^{-}, \mathrm{ONOO}^{-}$) species were studied in DMF solution by UV-vis and PA spectroscopy (Figure 2a, Figure S5). Insignificant changes in absorbance and PA gain to these reactive species lead to the conclusion that only $\mathrm{O}_{2}{ }^{\bullet-}$ induce this trigger effect. It was also found that the $\mathrm{O}_{2}{ }^{\bullet-}$-containing solution of $\mathbf{2}$ was stable for $>7$ days (Figure S15a) and $\mathbf{2}$ can be regenerated by treating the solution with citric acid (Figure $\mathrm{S} 15 \mathrm{~b})$.

Then, we performed PA spectroscopy with 2 and $\mathrm{F}^{-}$using TBAF, which showed a 16-fold intense PA-signal and a redshift of over $160 \mathrm{~nm}$ (observed $\mathrm{PA}_{\mathrm{Max}}: 815 \mathrm{~nm}$ ) (Figure $2 \mathrm{~b}$ ) compared to pure 2 . The dilution series PA spectra confirmed $\mathrm{F}^{-}$-activated 2 solutions could be detected down to $3 \mu \mathrm{M}$ (Figure S21). Furthermore, the detection limit of $\mathrm{F}^{-}$by 2 was also investigated by UVvis, and found that $400 \mathrm{nmol} / \mathrm{mL}$ of $\mathrm{F}^{-}$could be detected using $100 \mathrm{nmol} / \mathrm{mL}$ of 2 . Complete activation of UV-vis solution and thus saturation was achieved by around $2 \mu \mathrm{mol} / \mathrm{mL}$.

In addition to ROS, we investigated the effect of halides $\left(\mathrm{Cl}^{-}, \mathrm{Br}^{-}\right.$and $\mathrm{I}^{-}$as $\mathrm{Bu}_{4} \mathrm{~N}^{+} \mathrm{X}^{-}$salts) since 2 resembling calix[4]pyrroles are known to bind anions. ${ }^{40}$ Furthermore the effects of potassium and tetrabutyl ammonium cations (as KBr, and as hexafluoro phosphate salt $\mathrm{Bu}_{4} \mathrm{~N}^{+} \mathrm{PF}_{6}^{-}$) on 2 were investigated (Figure S5). None of the above ions changed the absorption spectra further indicating that the trigger effect was selectively caused by $\mathrm{O}_{2}^{\bullet-}$, and its mimic fluoride ion.

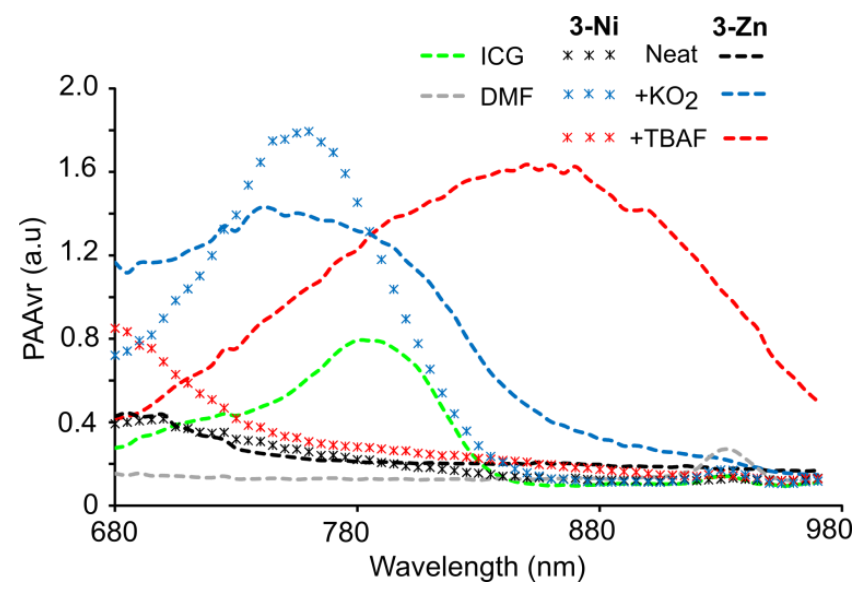

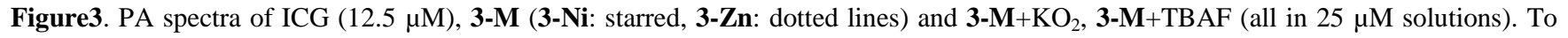
induce trigger response, excess $\mathrm{KO}_{2} / 18-\mathrm{C}-6$ and TBAF were added to $25 \mu \mathrm{M}$ solutions of $\mathbf{3}-\mathbf{M}$ and recorded PA immediately.

Table 1. Change in optical and photoacoustic properties of 1-M, 2, 3-Ni and 3-Zn, in response to added triggers

\begin{tabular}{|c|c|c|c|c|c|}
\hline No. & $\begin{array}{l}\text { UV-vis } \\
\lambda_{\operatorname{Max}}{ }^{\text {a] }} \\
\text { (PA Avr } \\
\text { at } \\
685 \mathrm{~nm} \\
{[\mathrm{~b}] \text { ) }}\end{array}$ & $\begin{array}{l}+\mathrm{O}_{2}^{\bullet-[\mathrm{c}]} \\
\mathrm{PA}_{\mathrm{Max}} \\
\mathrm{nm}(\mathrm{PA} \\
\mathrm{Avr})\end{array}$ & $\begin{array}{l}\mathrm{O}_{2}^{\bullet-} \\
\text { in- } \\
\text { duced } \\
\text { red } \\
\text { shift } \\
\text { in } \\
\mathrm{nm}^{[\mathrm{d}]} \\
(\mathrm{PA} \\
\text { signal } \\
\text { gain, }\end{array}$ & $\begin{array}{l}+\mathrm{F}^{-[\mathrm{c}]} \\
\mathrm{PA}_{\mathrm{Max}} \\
\text { in } \mathrm{nm} \\
\text { (PA } \\
\text { Avr) }\end{array}$ & $\begin{array}{l}\mathrm{F}^{-} \\
\text {induced } \\
\text { red } \\
\text { shift in } \\
\mathrm{nm}^{[\mathrm{d}]} \\
(\mathrm{PA} \\
\text { signal } \\
\text { gain } \\
\text { in- } \\
\text { fold })^{[\mathrm{e}]}\end{array}$ \\
\hline
\end{tabular}


in fold $)^{[\mathrm{e}]}$

\begin{tabular}{|c|c|c|c|c|c|}
\hline 2 & $\begin{array}{l}654 \\
(0.23)\end{array}$ & $\begin{array}{l}745 \\
(0.95)\end{array}$ & $\begin{array}{l}89 \\
(9.6)\end{array}$ & $\begin{array}{l}815 \\
(1.27)\end{array}$ & $\begin{array}{l}161 \\
(16)\end{array}$ \\
\hline $3-\mathrm{Ni}$ & $\begin{array}{l}661 \\
(0.40)\end{array}$ & $\begin{array}{l}760 \\
(0.95)\end{array}$ & $\begin{array}{l}99 \\
(4.9)\end{array}$ & $\begin{array}{l}680 \\
(0.85)\end{array}$ & $\begin{array}{l}19 \\
(2.1)\end{array}$ \\
\hline 3-Zn & $\begin{array}{l}690 \\
(0.44)\end{array}$ & $\begin{array}{l}740 \\
(1.43)\end{array}$ & $\begin{array}{l}50 \\
(6.4)\end{array}$ & $\begin{array}{l}875 \\
(1.63)\end{array}$ & $\begin{array}{l}185 \\
(6.5)\end{array}$ \\
\hline $1-2 \mathrm{H}$ & $\begin{array}{l}655 \\
(0.25)\end{array}$ & $\begin{array}{l}755 \\
(0.69)\end{array}$ & $\begin{array}{l}100 \\
(4.1)\end{array}$ & $\begin{array}{l}790 \\
(0.87)\end{array}$ & $\begin{array}{l}135 \\
(5.8)\end{array}$ \\
\hline 1-Ni & $\begin{array}{l}535 \\
(0.22)\end{array}$ & $\begin{array}{l}760 \\
(0.95)\end{array}$ & $\begin{array}{l}225 \\
(5)\end{array}$ & $\begin{array}{l}680 \\
(0.76)^{[\mathrm{f}]}\end{array}$ & $\begin{array}{l}110^{[f]} \\
(3.5)\end{array}$ \\
\hline $1-Z n$ & $\begin{array}{l}606 \\
(0.18)\end{array}$ & $\begin{array}{l}740 \\
(0.84)\end{array}$ & $\begin{array}{l}134 \\
(5)\end{array}$ & $\begin{array}{l}875 \\
(1.41)\end{array}$ & $\begin{array}{l}269 \\
(10.5)\end{array}$ \\
\hline
\end{tabular}

[a] The farthest absorption band maxima in UV-vis; [b] Found PA Avr $(25 \mu \mathrm{M}$, in DMF) at $685 \mathrm{~nm}$ was taken when no $\lambda_{\text {Max }}$ in the PA measured range was available; [c] The observed PA Avr (a.u) of excess trigger contained $25 \mu \mathrm{M}$ solutions injected into a tube phantom $(0.38 \mathrm{~mm}$ i.d. $)$; [d] The redshift was calculated as difference from absorption and PA maxima, when no PA band above $680 \mathrm{~nm}$ was available;[e] Gain ratios for triggers were determined by dividing found PA Avr (a.u) at $\mathrm{PA}_{\mathrm{Max}}$ with that of neat solution at the same wavelength; [f] PA signal at $680 \mathrm{~nm}$ was taken as the observed $\lambda_{\text {Max }}$ in UV-vis was at $645 \mathrm{~nm}$.

and 15.7-fold for $\mathrm{O}_{2}{ }^{--}$and $\mathrm{F}^{-}$triggers, respectively. The metallated porphodimethenes (3-M) solutions gave over 5-fold gain for $\mathrm{O}_{2}{ }^{--}$. This indicates that 2 can be highly suitable for superoxide sensing PA imaging applications.

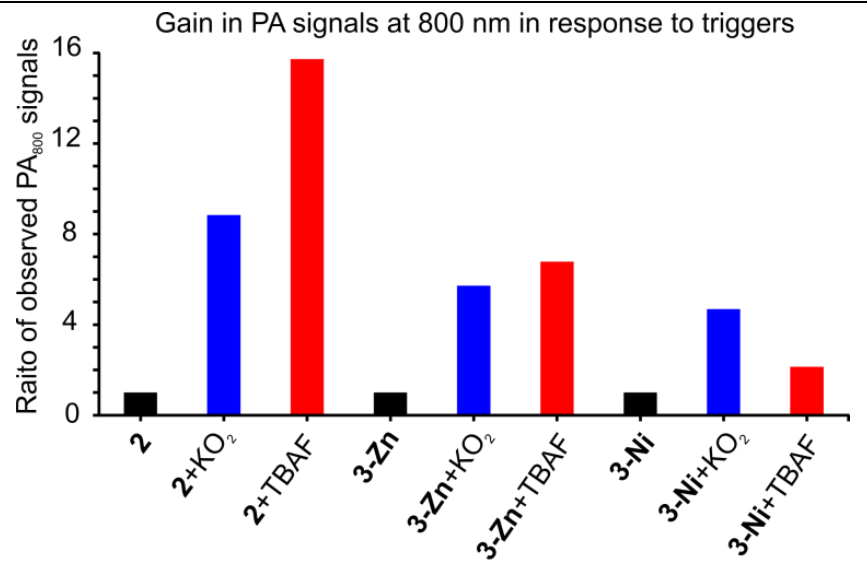

Figure 4. Gain in PA signals at $800 \mathrm{~nm}$ for compounds 2, 3-Zn and 3-Ni (in $25 \mu \mathrm{M}$ solutions) after adding $\mathrm{O}_{2}{ }^{--}$and $\mathrm{F}^{-}$triggers. PA gain ratio was taken as 1 , by default, for without trigger added solutions. Excess $\mathrm{KO}_{2} / 18-\mathrm{C}-6$ and TBAF were added to $25 \mu \mathrm{M}$ solutions of 2 , 3$\mathbf{M}$ to induce trigger response. Standard deviation from three measurements of all the solutions was below $5 \%$.

Subsequently, we explored the response of porphyrins 1-M $(\mathrm{M}=2 \mathrm{H}, \mathrm{Ni}, \mathrm{Zn})$ to both triggers. For this purpose, all 1-M were first titrated with $\mathrm{KO}_{2}$ in the presence of 18-crown-6 (18-C-6) (in DMF or $\mathrm{CH}_{2} \mathrm{Cl}_{2}$ ) and UV-vis were obtained and compared with those from TBAF titration (Figure S2, S3, S9-S12). In detail, the UV-vis absorption pattern of 1-M changed similarly in response to $\mathrm{O}_{2}{ }^{\bullet-}$ and $\mathrm{F}^{-}$ions: a loss of Soret and $\mathrm{Q}$ bands of porphyrin and appearance of a broad absorption band above $650 \mathrm{~nm}$ were observed. Moreover, there was a lower redshift for $\mathrm{O}_{2}{ }^{\bullet-}$ than for $\mathrm{F}^{-}$in $\mathbf{1 - 2 H}, \mathbf{1 - Z n}$, whereas with 1-Ni, a higher redshift for $\mathrm{O}_{2}{ }^{\bullet-}$ than for $\mathrm{F}^{-}$ was found.

PA spectroscopy was performed, analogously to $\mathbf{2}$, with 1-2H (in DMF, conc.: $67 \mu \mathrm{M}$ ), 1-Ni, 1-Zn (in DMF, conc. : $100 \mu \mathrm{M}$ ) and ICG (in DMF conc.: $7.8 \mu \mathrm{M}$ ) to assess its potential as trigger responsive imaging agent. Pristine 1-2H's PA signal was almost

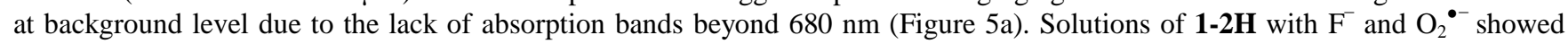


trigger-induced photoacoustic signals, the PA maximum at $755 \mathrm{~nm}$ and $790 \mathrm{~nm}$, with an average 6- and 4-fold increase in PA signals, respectively (see Table 1). In order to evaluate the sensitivity of PA imaging for $\mathbf{1 - 2} \mathbf{H}+\mathrm{KO}_{2}$ and for $\mathbf{1 - 2 H}+\mathrm{TBAF}$, dilution series were generated,
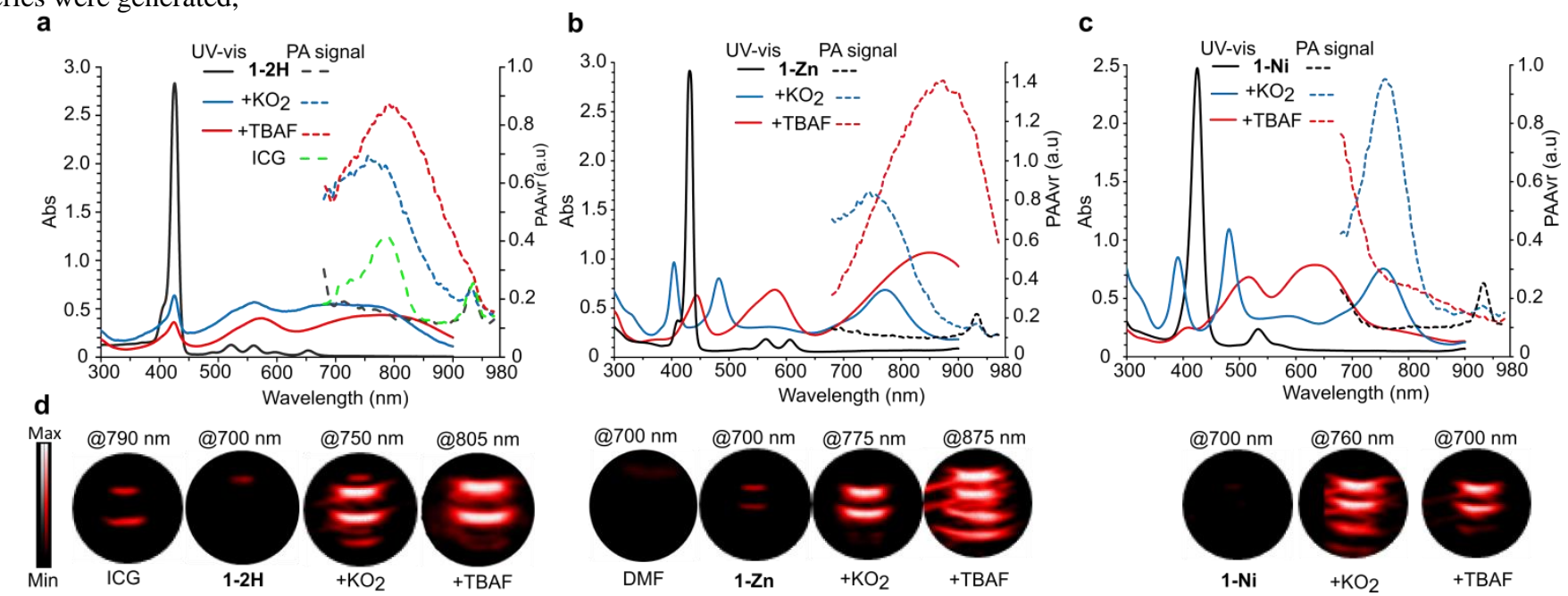

Figure5. $\mathrm{O}_{2}{ }^{\bullet-}$ and $\mathrm{F}^{-}$trigger characteristic shifts in the UV-vis (full lines, left axis) and PA spectra (dotted lines, right axis) of the chromophores 1-M $(\mathrm{M}=2 \mathrm{H}, \mathrm{Zn}, \mathrm{Ni})$ in DMF solution (excess $\mathrm{TBAF}, \mathrm{KO}_{2} / 18-\mathrm{C}-6$ were added to the 1-M solutions to induce trigger response). a) 1-2H, UV-vis spectra at conc. $10.5 \mu \mathrm{M}$, PA spectra at conc. $66 \mu \mathrm{M}$ and ICG PA spectra at conc. $7.8 \mu \mathrm{M}$ in DMF; b) 1-Zn, UV-vis spectra at conc. $10 \mu \mathrm{M}$ and PA spectra at conc. $25 \mu \mathrm{M}$; c) 1-Ni, UV-vis spectra at conc. $10 \mu \mathrm{M}$ and PA spectra at conc. $25 \mu \mathrm{M}$. d) PA images of tube phantoms filled with 1-M solutions with and without activation by $\mathrm{KO}_{2}$ or TBAF recorded at their respective maxima. ICG and DMF loaded phantoms were measured along as controls.

and PA signal could reliably be detected for concentrations of $8.3 \mu \mathrm{M}$.

Further, PA spectroscopy measurements were performed using the metallated porphyrins $\mathbf{1 - Z n}, \mathbf{1 - N i}$ in DMF solutions, analogously to 1-2H. As expected, 1-Ni, 1-Zn generated no PA signals even in concentrations as high as $100 \mu \mathrm{M}$ (Figure S22, S23). This is due to the absence of absorption bands in the PA imaging range (i.e. $>680 \mathrm{~nm}$ ). In response to $\mathrm{O}_{2}{ }^{\bullet-}$ and $\mathrm{F}^{-}$, the absorption maximum of 1-Zn was red shifted by $134 \mathrm{~nm}\left(\mathrm{PA}_{\mathrm{Max}}\right.$ : $740 \mathrm{~nm})$ and $269 \mathrm{~nm}\left(\mathrm{PA}_{\mathrm{Max}}: 875 \mathrm{~nm}\right)$, and exhibited a 5-fold and a 10.5-fold gain in PA signals, respectively (Figure 5b, and Figure S24, S26). Moreover, we also observed that the stability of $\mathrm{O}_{2}{ }^{\bullet-}$ containing $\mathbf{1 - Z n}$ solution was lower and the PA signal intensity of approximately $30 \mathrm{~min}$ old solution was far below that of a freshly prepared one (see Figure S25, S26). This was due to oxidative decomposition of the formed $\mathbf{3 - Z n}$ in the presence of $\mathrm{O}_{2}{ }^{\bullet-}$, which was also observed in the synthetic process. In contrary, the solution of $\mathbf{2}$ in the presence of $\mathrm{O}_{2}{ }^{--}$exhibited high stability, for more than 7 days at $4{ }^{\circ} \mathrm{C}$ (see Figure S6) without any decomposition.

In the case of $\mathbf{1 - N i}$, the above triggers showed an opposite effect, i.e. a redshift of $225 \mathrm{~nm}$ for $\mathrm{O}_{2}^{\bullet-}\left(\mathrm{PA}_{\mathrm{Max}}: 760 \mathrm{~nm}\right)$, and only $105 \mathrm{~nm}$ for $\mathrm{F}^{-}\left(\lambda_{\text {Max }}: 645 \mathrm{~nm}\right)$. The observed gain in PA signal for $\mathrm{O}_{2}^{\bullet-}$ trigger was 5-fold (calculated at $760 \mathrm{~nm}$ ) and 3.5 -fold for $\mathrm{F}^{-}$(calculated from $680 \mathrm{~nm}$ PA signal). Furthermore, to explore the detection limit of the trigger activated $\mathbf{1 - N i}$, 1-Zn solutions, dilution series were prepared and PA spectroscopy was performed. We found that the PA signal can be detected down to a $3.1 \mu \mathrm{M}$ concentration (Figure S24-S28). Therefore, we conclude that porphyrins $\mathbf{1 - M}(\mathrm{M}=2 \mathrm{H}, \mathrm{Zn}, \mathrm{Ni}) \mathrm{might}$ also be suitable for $\mathrm{O}_{2}{ }^{\circ-}$ trigger responsive PA imaging applications.

\section{Biocompatibility and signal attenuation}

The porphyrins and oxoporphyrinogens investigated above are hydrophobic and thus need to be formulated with excipients to obtain aqueous solubility. Cremophore EL (CrEL) formulation is a commonly used approach to enhance the water solubility of hydrophobic pharmaceutical compounds, and thus was applied here. As the stability and trigger response of the oxoporphyrinogen 2 was found to be higher than the others, we used $\mathbf{2}$ in CrEL formulation (2:CrEL) in further studies.

The probe 2 was encapsulated in $0.15 \% \mathrm{CrEL}$ (w/w) and the resulting 2:CrEL formulation was prepared in phosphate buffer saline solution. The biocompatibility of 2:CrEL was studied on human prostate cancer PC3 cells using the XTT (2,3-Bis-(2methoxy-4-nitro-5-sulfophenyl]-2H-tetrazolium-5-

carboxyanilide salt) assay. We found that doses of up to $50 \mu \mathrm{M}$ were compatible (Figure 6). For trigger activated PA imaging, as proven in dilution series experiments, concentrations of up to $3 \mu \mathrm{M}$ are sufficient to generate a PA signal, hence, $\mathbf{2}$ is suitable for further studies. 
Table 2. Compilation of observed properties with respective to optimal need

\begin{tabular}{|c|c|c|c|c|}
\hline No. & $\begin{array}{l}\text { Stabil- } \\
\text { ity }\end{array}$ & $\begin{array}{l}\text { Biocom- } \\
\text { patibility }\end{array}$ & $\begin{array}{lr}\text { Red shift in } \\
\lambda_{\text {PAMax }} \text { (in } \\
\mathrm{nm} \text { ) } & \text { for } \\
\mathrm{O}_{2}{ }^{\bullet-} & \end{array}$ & $\begin{array}{l}\text { Gain in } \\
\text { PA sig- } \\
\text { nal (fold) } \\
\text { for } \mathrm{O}_{2}^{\bullet-}\end{array}$ \\
\hline 2 & +++ & +++ & 89 & 9.6 \\
\hline $3-\mathrm{Ni}$ & + & n.a. & 99 & 4.9 \\
\hline 3-Zn & + & n.a. & 50 & 6.4 \\
\hline $1-2 H$ & +++ & ++ & 100 & 5.8 \\
\hline $1-\mathrm{Ni}$ & +++ & ++ & 225 & 5 \\
\hline $1-Z n$ & +++ & ++ & 134 & 5 \\
\hline
\end{tabular}

n.a.: not measured; +++: very good

++: good ; +: moderate

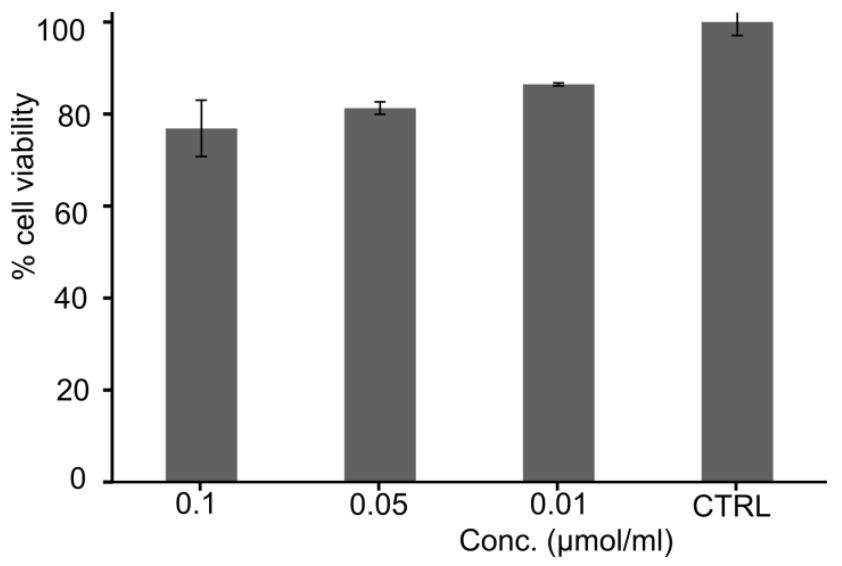

Figure6. Viability of PC3 cells after incubation with 2:CrEL in different concentrations (XTT-assay). CTRL: cells in culture medium with only $0.15 \%$ CrEL.

Subsequently, to mimic in vivo light absorption and ultrasound attenuation conditions, we performed PA imaging in a chicken muscle phantom. Polythene tubes containing solutions of 2 and $2+\mathrm{KO}_{2}$ (conc.: $125 \mu \mathrm{M}$ and $20 \mu \mathrm{M}$ ) we replaced within a chicken muscle and PA imaging was performed (Figure 7). The $\mathrm{O}_{2}{ }^{\bullet-}$-activated solution was clearly visible in $11-16 \mathrm{~mm}$ depths (Figure S35). Higher depth is not possible with the commercial Vevo LAZR device, as it is engineered to produce a focussed light at $11 \mathrm{~mm}$ depth with diffused light a further few millimeters deeper. The neat $\mathbf{2}$ in chicken muscle showed no PA signal at $750 \mathrm{~nm}$ even at $125 \mu \mathrm{M}$, but gave a very weak signal at $700 \mathrm{~nm}$. These confirm that probe 2 in combination with superoxide trigger may be well suited for in vivo PA imaging applications.

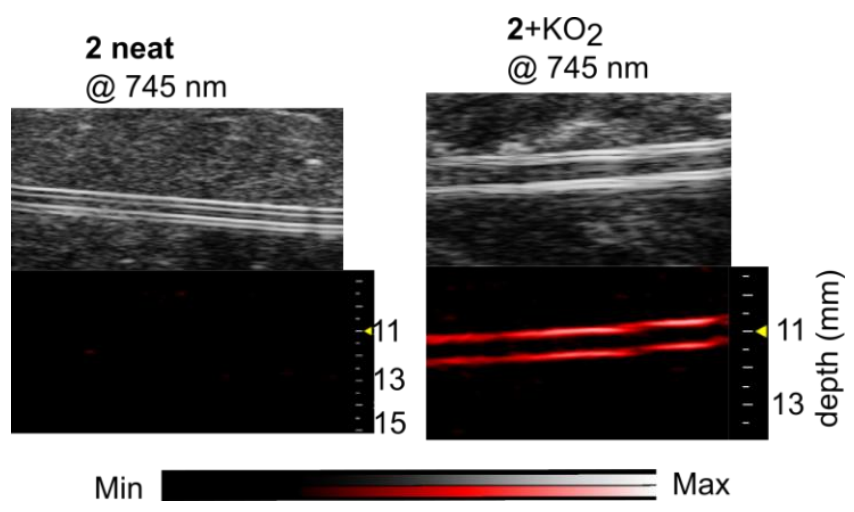

Figure7. Ultrasound B-mode (top) and (bottom) PA images (at their $\left.\mathrm{PA}_{\mathrm{Max}}\right)$ of neat 2 (left, conc. : $125 \mu \mathrm{M}$ ) and $2+\mathrm{KO}_{2} / 18-\mathrm{C}-6$ (right, conc. : $20 \mu \mathrm{M}$ ) in chicken muscle.

\section{Photostability}

The oxoporphyrinogens were investigated for their photostability using red light irradiation (680-700 nm LED, with power output $\left.100 \mathrm{mJcm}^{-2}\right){ }^{41}$ After irradiation of the solution of 2 (in DMF, $125 \mu \mathrm{M}$ ) for $40 \mathrm{~min}$ (total power: $240 \mathrm{Jcm}^{-2}$ ) an $18 \%$ lower absorbance than in the initial solution was found by UV-vis spectroscopy (Figure S7). On the contrary, irradiation of 3-Zn and 3-Ni, for 40 min showed only 1-3 \% absorbance loss. For PA imaging, the applied power produces intensity in the range of $20-100 \mathrm{mJs}^{-1}$ and imaging can be completed within $30 \mathrm{sec}$. Hence, the photobleaching of $\mathbf{2}$ is expected to be less $0.3 \%$ in PA studies, which is minimal.

\section{Conclusions}

Here we showed for the first time superoxide sensing probes for photoacoustic imaging based on porphyrin, oxoporphyrinogen and porphodimethene dyes. These porphyrins are robust and biocompatible molecules, which can be used to visualize the presence of highly reactive species such as $\mathrm{O}_{2}{ }^{--}$by photoacoustic imaging. We found that the oxoporphyrinogen 2 and its porphyrin precursor (1-2H) exhibit similar stimuli-responsive characteristics with a gain in PA signals and a red-shift in PA maxima. In detail, in response to $\mathrm{O}_{2}{ }^{\bullet-}$, probe 2 exhibited the highest gain in the PA signal (9.6 fold at $\mathrm{PA}_{\mathrm{Max}}: 745 \mathrm{~nm}$ ), while 1-Ni showed the highest red shift $(225 \mathrm{~nm})$ with a 5-fold gain in PA signal. The metal-free 1-2H reacted as well with $\mathrm{O}_{2}{ }^{\circ-}$ and showed an over $100 \mathrm{~nm}$ red shift and an up to 5-fold increase in PA signal. Of those, the metalfree oxoporphyrinogen 2 was convinced by its high biocompatibility and stability towards $\mathrm{O}_{2}{ }^{\bullet-}$ after activation. Thus, we are planning to explore its potential, with in vivo suitable compounds for superoxide imaging applications in future studies.

\section{ASSOCIATED CONTENT}

Supporting Information. UV-vis, fluorescence spectra, titrations, NMR and ESI-MS spectra and photoacoustic imaging data.

"This material is available free of charge via the Internet at http://pubs.acs.org."

\section{AUTHOR INFORMATION}




\section{Corresponding Author}

*sbanala@ukaachen.de

\section{Funding Sources}

Excellence Initiative of the German federal and state governments through the I3TM Seed Fund Program and I3TM Step2Projects.

\section{Notes}

The authors declare no conflict of interest.

\section{ACKNOWLEDGMENT}

Prof. Dr. Twan Lammers is acknowledged for his helpful suggestions in the preparation of manuscript.

\section{ABBREVIATIONS}

PA, photoacoustic; H.V., high vacuum; MS, mass spectrometry; DMF, N,N-dimethylformamide, $\mu \mathrm{M}$, micromolar.

\section{REFERENCES}

(1) Reactive Oxygen Species in Biology and Human Health; Ahmad, S. I., Ed.; CRC Press: New York, 2016.

(2) Hayyan, M.; Hashim, M. A.; AlNashef, I. M. Superoxide Ion: Generation and Chemical Implications. Chem. Rev. 2016, 116, 30293085.

(3) Egea, J.; etal. European contribution to the study of ROS: A summary of the findings and prospects for the future from the COST action BM1203 (EU-ROS). Redox Biol. 2017, 13, 94-162.

(4) Chen, X.; Wang, F.; Hyun, J. Y.; Wei, T.; Qiang, J.; Ren, X.; Shin, I.; Yoon, J. Recent progress in the development of fluorescent, luminescent and colorimetric probes for detection of reactive oxygen and nitrogen species. Chem. Soc. Rev. 2016, 45, 2976-3016.

(5) Wang, L. V.: Photoacoustic Imaging and Spectroscopy; CRC Press: Boca Raton, FL, 2009.

(6) Manohar, S.; Razansky, D. Photoacoustics: a historical review. Advances in Optics and Photonics 2016, 8, 586-617.

(7) Karabutov, A. A.; Savateeva, E. V.; Oraevsky, A. A. Optoacoustic Tomography: New Modality of Laser Diagnostic Systems. Laser Phys. 2003, 13, 711-723.

(8) Wang, L. V.; Hu, S. Photoacoustic Tomography: In Vivo Imaging from Organelles to Organs. Science 2012, 335, 1458-1462.

(9) Ntziachristos, V.; Razansky, D. Molecular Imaging by Means of Multispectral Optoacoustic Tomography (MSOT). Chem. Rev. 2010, 110, 2783-2794.

(10)Zackrisson, S.; van de Ven, S. M. W. Y.; Gambhir, S. S. Light In and Sound Out: Emerging Translational Strategies for Photoacoustic Imaging. Cancer Res. 2014, 74, 979-1004.

(11)Ivankovic, I.; Merčep, E.; Schmedt, C.-G.; Deán-Ben, X. L.; Razansky, D. Real-time Volumetric Assessment of the Human Carotid Artery: Handheld Multispectral Optoacoustic Tomography. Radiology 2019, 181325.

(12)Bayer, C. L.; Joshi, P. P.; Emelianov, S. Y. Photoacoustic imaging: a potential tool to detect early indicators of metastasis. Expert Rev. Med. Devices 2013, 10, 125-134.

(13)Levi, J.; Kothapalli, S.-R.; Bohndiek, S.; Yoon, J.-K.; Dragulescu-Andrasi, A.; Nielsen, C.; Tisma, A.; Bodapati, S.; Gowrishankar, G.; Yan, X.; Chan, C.; Starcevic, D.; Gambhir, S. S. Molecular Photoacoustic Imaging of Follicular Thyroid Carcinoma. Clin. Cancer Res. 2013, 19, 1494-1502.

(14)Diot, G.; Metz, S.; Noske, A.; Liapis, E.; Schroeder, B.; Ovsepian, S. V.; Meier, R.; Rummeny, E. J.; Ntziachristos, V. MultiSpectral Optoacoustic Tomography (MSOT) of human breast cancer. Clin Cancer Res 2017, 23, 6912-6922.
(15)Waldner, M. J.; Knieling, F.; Egger, C.; Morscher, S.; Claussen, J.; Vetter, M.; Kielisch, C.; Fischer, S.; Pfeifer, L.; Hagel, A.; Goertz, R. S.; Wildner, D.; Atreya, R.; Strobel, D.; Neurath, M. F. Multispectral Optoacoustic Tomography in Crohn's Disease: Noninvasive Imaging of Disease Activity. Gastroenterology 2016, 151, 238-240.

(16)Stoffels, I.; Morscher, S.; Helfrich, I.; Hillen, U.; Leyh, J.; Burton, N. C.; Sardella, T. C. P.; Claussen, J.; Poeppel, T. D.; Bachmann, H. S.; Roesch, A.; Griewank, K.; Schadendorf, D.; Gunzer, M.; Klode, J. Metastatic status of sentinel lymph nodes in melanoma determined noninvasively with multispectral optoacoustic imaging. Sci. Transl. Med. 2015, 7, 317ra199-317ra199.

(17)Gerling, M.; Zhao, Y.; Nania, S.; Norberg, J. K.; Verbeke, C. S.; Englert, B.; Kuiper, R. V.; Bergström, Å.; Hassan, M.; Neesse, A.; Löhr, J. M.; Heuchel, R. L. Real-Time Assessment of Tissue Hypoxia In Vivo with Combined Photoacoustics and High-Frequency Ultrasound. Theranostics 2014, 4, 604-613.

(18)Manohar, S.; Vaartjes, S. E.; Hespen, J. C. G. v.; Klaase, J. M.; Engh, F. M. v. d.; Steenbergen, W.; Leeuwen, T. G. v. Initial results of in vivo non-invasive cancer imaging in the human breast using nearinfrared photoacoustics. Opt. Express 2007, 15, 12277-12285.

(19)Reber, J.; Willershäuser, M.; Karlas, A.; Paul-Yuan, K.; Diot, G.; Franz, D.; Fromme, T.; Ovsepian, S. V.; Bézière, N.; Dubikovskaya, E.; Karampinos, D. C.; Holzapfel, C.; Hauner, H.; Klingenspor, M.; Ntziachristos, V. Non-invasive Measurement of Brown Fat Metabolism Based on Optoacoustic Imaging of Hemoglobin Gradients. Cell Metab. 2018, 27, 689-701.e684.

(20)Miao, Q.; Pu, K. Emerging Designs of Activatable Photoacoustic Probes for Molecular Imaging. Bioconjugate Chemistry 2016, 27, 2808-2823.

(21)Xie, C.; Zhen, X.; Lyu, Y.; Pu, K. Nanoparticle Regrowth Enhances Photoacoustic Signals of Semiconducting Macromolecular Probe for In Vivo Imaging. Adv. Mater. 2017, 29, 1703693.

(22)Chen, Q.; Liang, C.; Sun, X.; Chen, J.; Yang, Z.; Zhao, H.; Feng, L.; Liu, Z. H2O2-responsive liposomal nanoprobe for photoacoustic inflammation imaging and tumor theranostics via in vivo chromogenic assay. Proc. Natl. Acad. Sci. USA 2017, 114, 5343.

(23)Nie, L.; Chen, X. Structural and functional photoacoustic molecular tomography aided by emerging contrast agents. Chem. Soc. Rev. 2014, 43, 7132-7170.

(24)Weber, J.; Beard, P. C.; Bohndiek, S. E. Contrast agents for molecular photoacoustic imaging. Nat. Meth. 2016, 13, 639-650.

(25)Repenko, T.; Fokong, S.; De Laporte, L.; Go, D.; Kiessling, F.; Lammers, T.; Kuehne, A. J. C. Water-soluble dopamine-based polymers for photoacoustic imaging. Chem. Commun. 2015, 51, 60846087.

(26)Banala, S.; Fokong, S.; Brand, C.; Andreou, C.; Kräutler, B.; Rueping, M.; Kiessling, F. Quinone-fused porphyrins as contrast agents for photoacoustic imaging. Chem. Sci. 2017, 8, 6176-6181.

(27)Li, J.; Pu, K. Development of organic semiconducting materials for deep-tissue optical imaging, phototherapy and photoactivation. Chem. Soc. Rev. 2019, 48, 38-71.

(28)Fu, Q.; Zhu, R.; Song, J.; Yang, H.; Chen, X. Photoacoustic Imaging: Contrast Agents and Their Biomedical Applications. Adv. Mater. 2019, 31, 1805875.

(29)Yin, C.; Zhen, X.; Fan, Q.; Huang, W.; Pu, K. Degradable Semiconducting Oligomer Amphiphile for Ratiometric Photoacoustic Imaging of Hypochlorite. ACS Nano 2017, 11, 4174-4182.

(30)Zhang, J.; Zhen, X.; Upputuri, P. K.; Pramanik, M.; Chen, P.; $\mathrm{Pu}, \mathrm{K}$. Activatable Photoacoustic Nanoprobes for In Vivo Ratiometric Imaging of Peroxynitrite. Adv. Mater. 2016, 29, 1604764.

(31)Dragulescu-Andrasi, A.; Kothapalli, S.-R.; Tikhomirov, G. A.; Rao, J.; Gambhir, S. S. Activatable Oligomerizable Imaging Agents for Photoacoustic Imaging of Furin-Like Activity in Living Subjects. $J$. Am. Chem. Soc. 2013, 135, 11015-11022.

(32)Pu, K.; Shuhendler, A. J.; Jokerst, J. V.; Mei, J.; Gambhir, S. S.; Bao, Z.; Rao, J. Semiconducting polymer nanoparticles as photoacoustic molecular imaging probes in living mice. Nat. Nanotechnol. 2014, 9, 233-239. 
(33)Klötzner, D.-P.; Klehs, K.; Heilemann, M.; Heckel, A. A new photoactivatable near-infrared-emitting QCy7 fluorophore for singlemolecule super-resolution microscopy. Chem. Commun. 2017, 53, 9874-9877.

(34)Milgrom, L. R. The facile aerial oxidation of a porphyrin. Tetrahedron 1983, 39, 3895-3898.

(35)Shundo, A.; Hill, J. P.; Ariga, K. Toward Volatile and Nonvolatile Molecular Memories: Fluorescence Switching Based on Fluoride-Triggered Interconversion of Simple Porphyrin Derivatives. Chem. Eur. J. 2009, 15, 2486-2490.

(36)Sawyer, D. T.; Valentine, J. S. How super is superoxide? Acc. Chem. Res. 1981, 14, 393-400.

(37)Lindsey, J. S.; Schreiman, I. C.; Hsu, H. C.; Kearney, P. C.; Marguerettaz, A. M. Rothemund and Adler-Longo Reactions Revisited: Synthesis of Tetraphenylporphyrins under Equilibrium Conditions. $J$. Org. Chem. 1987, 52, 827-836.

(38)Betoni Momo, P.; Pavani, C.; Baptista, M. S.; Brocksom, T. J.; Thiago de Oliveira, K. Chemical Transformations and Photophysical Properties of meso-Tetrathienyl-Substituted Porphyrin Derivatives. Eur. J. Org. Chem. 2014, 2014, 4536-4547.

(39)Wali, M. A.; Suleiman, S. A.; Kadoumi, O. F.; Nasr, M. A. Superoxide radical concentration and superoxide dismutase (SOD) enzyme activity in varicose veins. Ann. Thorac. Cardiovasc. Surg. 2002, 8, 286-290.

(40)Kim, D. S.; Sessler, J. L. Calix[4]pyrroles: versatile molecular containers with ion transport, recognition, and molecular switching functions. Chem. Soc. Rev. 2015, 44, 532-546.

(41)de Boer, E.; Warram, J. M.; Hartmans, E.; Bremer, P. J.; Bijl, B.; Crane, L. M. A.; Nagengast, W. B.; Rosenthal, E. L.; van Dam, G. M. A Standardized Light-Emitting Diode Device for Photoimmunotherapy. J. Nucl. Med. 2014, 55, 1893-1898. 
TOC Figure:

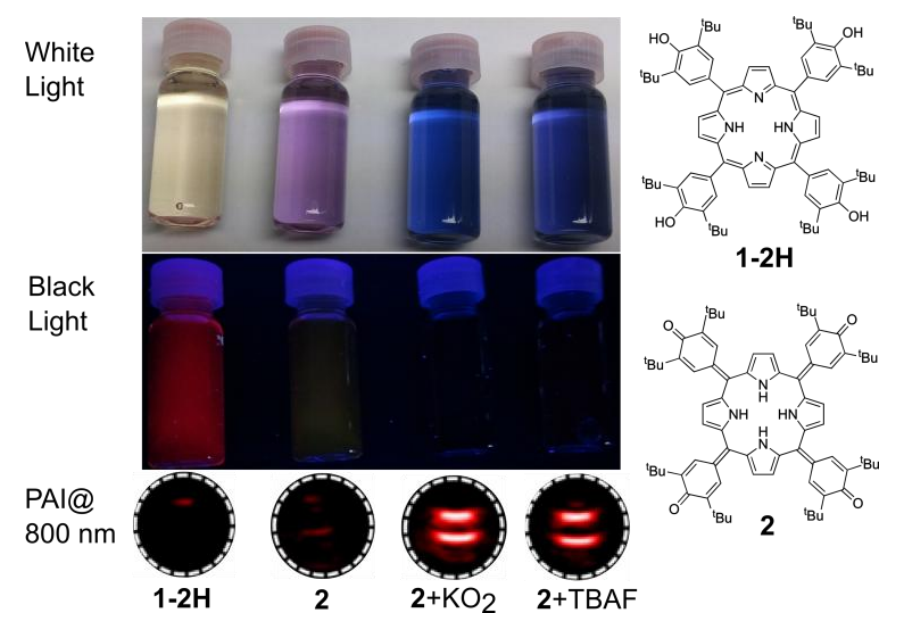

